\title{
O ESPAÇO URBANO E A PRODUÇÃO DE SENTIDOS
}

\author{
The urban space and the sense production
}

Gilberto Nazareno Telles Sobral (UNEB)

\begin{abstract}
RESUMO: Estudar uma cidade é procurar entender as tensões humanas e materiais que preenchem seus espaços, seja como forma de resistência ou de transformações daqueles que nela transitam. Os espaços urbanos são ocupados pela sua arquitetura, manifestações culturais, por indivíduos e seus corpos, entre tantas outras coisas, os quais (re)constroem discursivamente estes espaços. A fim de analisar como o espaço urbano significa, tomamos como aporte teórico a Análise do Discurso de linha francesa filiada a Michel Pêcheux e como objeto de estudo dois espaços urbanos que passaram por processos de revitalização: o Centro Histórico de Salvador e a Rua 13 de Maio, mais conhecida como Beco da Energia, em Feira de Santana.
\end{abstract}

PALAVRAS-CHAVE: Espaço urbano; Salvador; Beco da Energia; Discurso.

\begin{abstract}
Studying a city is like trying to understand the human and material tensions that fill in its spaces either as a way of resistence or transformation of those who live in it. Urban spaces are occupied by its architecture, cultural manifestations, individuals and their bodies among many other things which (re)build discursively these spaces. The theoretical support of French Discourse Analysis by Michel Pêcheux was used in order to analyze how the urban space means. Two urban spaces which went through processes of revitalization were analyzed: the historic center in Salvador and the 13 de Maio Street in Feira de Santanta, better known as the Beco da Energia.
\end{abstract}

KEYWORDS: Urban space; Salvador; Beco da Energia; Discourse. 


\section{Considerações iniciais}

Estudar uma cidade é procurar entender as tensões humanas e materiais que preenchem seus espaços, seja como forma de resistência ou de transformações daqueles que nela transitam. Os espaços urbanos são ocupados pela sua arquitetura, manifestações culturais, por indivíduos e seus corpos, entre tantas outras coisas, os quais (re)constroem discursivamente estes espaços.

Segundo Orlandi (2004), observar a cidade é procurar compreender as alterações que se dão na natureza humana e social. Daí um dos motivos que levam ao interesse em se estudar cidade.

Tratar do discurso é pensar na produção de sentidos, logo, neste processo, consideramos dois elementos como essenciais: o sujeito, aqui compreendidos como seres socialmente construídos a partir da interpelação ideológica pela sua inscrição numa dada formação discursiva, e a história, ou seja, não é o sujeito que instaura os sentidos, pois estes significam antes e em outro lugar.

O discurso constitui-se de uma prática, não apenas de representação do mundo: implica uma exterioridade à língua, presentifica-se no social e inscreve-se na história.

Há vários motivos para estudar a cidade, entre eles a

[...] riqueza que se mostra na relação do indivíduo com os outros indivíduos e com tudo que constitui a cidade. Heterogeneidade mas padronização, subordinação a exigências da comunidade maior na medida em que faz parte de movimentos coletivos, mas, ao mesmo tempo, dispersão, e, ainda, individualidade. Temos então a mobilidade do indivíduo no campo de um grande número de indivíduos diferentes concentrados em um mesmo espaço urbano (ORLANDI, 2004, p. 12).

O discurso urbano, nosso objeto de estudo, materializa-se de diversas formas, isto é, nas suas construções, nas pichações, nos grafites, nos nomes de bairros e ruas, nos corpos, entre outras, e as transformações pelas quais passam os espaços urbanos clamam por novos sentidos.

Duas cidades do Estado da Bahia têm sido meus objetos de estudo: Salvador, a capital, e Feira de Santana, segundo maior município do Estado, visando à compreensão da construção e circulação de sentidos em diversos espaços urbanos.

A cidade do Salvador, por ser a primeira capital do Brasil, sempre teve sua importância no cenário nacional brasileiro, destacando-se, ao longo dos anos, pela sua relevância histórica e cultural. Contemporaneamente, por ser uma cidade histórica e 
muito pelo carnaval que realiza, representa um polo cultural e turístico, atraindo, anualmente, muitos turistas das mais diversas partes do país e estrangeiros, o que proporciona o surgimento dos mais diversos discursos sobre a cidade. Tema de músicas de muitos compositores, Salvador já foi denominada de terra da felicidade.

Feira de Santana destaca-se como importante centro urbano, político, econômico e comercial do interior da Bahia, além do destaque na área educacional, sediando uma das melhores escolas do país, como o Colégio Helyos, além da Universidade Estadual de Feira de Santana (UEFS), da Universidade Federal do Recôncavo da Bahia (UFRB), além de faculdades particulares, do Instituto Federal da Bahia (IFBA) e do Centro de Educação Tecnológica do Estado da Bahia (CETEB).

Neste trabalho, apresentamos um recorte da pesquisa Sujeitos e Sentidos no Espaço Urbano, mais especificamente, um olhar no Centro Histórico de Salvador e no Beco da Energia, localizado em Feira de Santana, espaços urbanos que passaram por importantes processos de revitalização.

Com os estudos fundamentados nos pressupostos teóricos da Análise do Discurso francesa, buscamos compreender como os referidos espaços urbanos se constituem discursivamente em materialidades diversas.

\section{Mobilizando algumas noções da Análise do Discurso}

Numa perspectiva discursiva, o objeto de estudo é o discurso, isto é, uma prática de linguagem que implica, ao mesmo tempo, o social, o histórico, o simbólico e o ideológico, é uma ação do sujeito sobre o mundo.

Segundo Orlandi (2012, p. 26),

[...] a Análise de Discurso visa à compreensão de como um objeto simbólico produz sentido, como ele está investido de significância para e por sujeitos. Essa compreensão, por sua vez, implica em explicar como o texto organiza os gestos de interpretação que relacionam sujeitos e sentidos. Produzem-se assim novas práticas de leituras.

O discurso, enquanto efeito de sentido entre interlocutores, é uma construção sócio-histórica, que implica uma exterioridade à língua. Assim, é considerado como objeto construído a partir das condições de produção, que sinaliza o sentido e a posição que o sujeito ocupa ao materializar um determinado enunciado. 
Daí a concepção de que o sujeito é historicamente constituído. O indivíduo é interpelado pela ideologia e, assim, constitui-se sujeito do discurso, o qual, sendo dotado de inconsciente, não se dá conta dessa interpelação. Segundo Orlandi (2006, p.19), “dessa interpelação do indivíduo em sujeito resulta uma forma-sujeito histórica". O lugar do sujeito é construído pela função social que ele exerce, a qual comporta a autoridade do sujeito e, consequentemente, o valor do seu dizer.

Para a AD, o sujeito é atravessado tanto pela ideologia quanto pelo inconsciente, resultando num sujeito cindido, clivado, descentrado, e que não é, portanto, a fonte e a origem dos processos discursivos; apenas tem esta ilusão, pois estes são determinados pela formação discursiva na qual se inscreve o sujeito falante. Na constituição do sujeito discursivo, dois aspectos devem ser considerados: o fato de que o sujeito é social, interpelado pela ideologia, e que é dotado de inconsciente.

Todo discurso é governado por formações ideológicas, que são projetadas na linguagem pelas formações discursivas, ou seja, "aquilo que, numa formação ideológica dada, isto é, a partir de uma posição dada numa conjuntura dada, determina o que pode e deve ser dito" (ORLANDI, 2006, p.17).

As formações discursivas são determinadas pelo interdiscurso, "constituído de todo dizer já-dito" (ORLANDI, 2006, p.18). Ainda segundo a autora (2006, p.18),

o interdiscurso é irrepresentável. Ele é constituído de todo dizer já-dito. Ele é o saber, a memória discursiva. Aquilo que preside todo dizer. É ele que fornece a cada sujeito sua realidade enquanto sistema de evidências e de significações percebidas, experimentadas. E é pelo funcionamento do interdiscurso que o sujeito não pode reconhecer sua subordinação-assujeitamento ao Outro.

Para Pêcheux e Fuchs ([1975] 1990), existem dois tipos de esquecimento no discurso: o esquecimento $\mathrm{n}^{\mathrm{o}} 1$, do campo ideológico, isto é, o sujeito tem a ilusão de ser a origem do seu dizer, e o esquecimento $n^{\circ} 2$, da ordem da enunciação, no qual o sujeito imagina ter o controle sobre o que diz, supondo a existência de uma relação unívoca entre o seu dizer e a realidade.

A seguir, tomando como base as discussões teóricas apresentadas anteriormente, discorreremos sobre a produção de sentidos nos espaços urbanos que constituem nosso objeto de estudo - Centro Histórico da cidade do Salvador, em particular, o Pelourinho, e o Beco da Energia, no município de Feira de Santana; por fim, apresentamos uma possível discussão do corpo como uma importante materialidade discursiva. 


\section{Olhares e sentidos no centro histórico da cidade de Salvador}

Em 1549 a cidade do Salvador tornou-se a capital do Brasil. Entre os séculos XVI e XVII foi a base para a sustentação da economia brasileira e, consequentemente, o grande centro econômico do país.

Com o declínio na importação do açúcar, em meados do século XVII, e o início da exploração de metais preciosos no centro-sul do país, Salvador deixa de ser a Capital do Brasil, que é transferida para a cidade do Rio de Janeiro. A cidade perdeu o prestígio econômico, mas, no decorrer dos anos, manteve sua importância histórica e cultural no cenário nacional, constituindo-se, assim, no século XX, num importante roteiro turístico do país, sendo conhecida pelos seus monumentos, igrejas, musicalidade, gastronomia e, principalmente, pelo Centro Histórico, em particular, o Pelourinho.

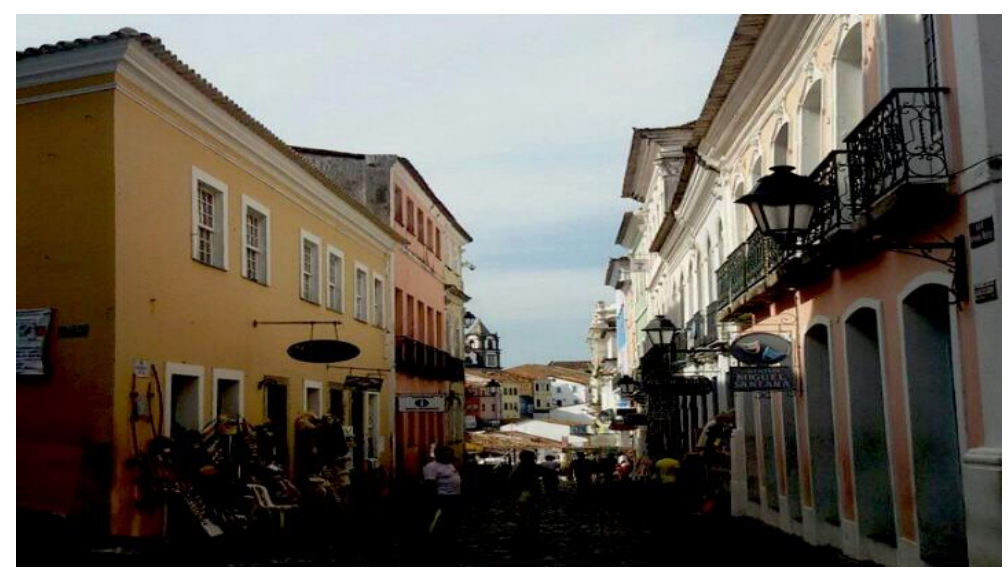

Figura 1: Pelourinho. Fotografia de Gilberto Sobral.

Considerando que múltiplos são os discursos que preenchem o Centro Histórico, significando-o e/ou re-significando-o, tomaremos, neste trabalho, algumas materialidades que o compõem para análise, considerando os diversos indivíduos que ali circulam e que, interpelados pelas mais variadas ideologias, subjetivam-se em sujeitos de discurso(s), aqui compreendido não como expressão de linguagem, não como texto, mas como efeito de sentido(s), discurso enquanto materialidade da ideologia.

Muitos dizeres sobre a cidade do Salvador estão relacionados com o Pelourinho como, por exemplo, "Salvador é uma cidade antiga", "Salvador é uma cidade musical", "Salvador é um dos destinos turísticos preferidos no Brasil", "Salvador é a cidade mais negra fora da África" - posições discursivas assumidas a partir de dizeres autorizados por formações discursivas que positivam a cidade, ao lado de dizeres como "Salvador é 
uma das cidades mais violentas do país", "Salvador é uma cidade pobre", entre tantos outros, que fazem parte do interdiscurso, isto é, dos já-ditos sobre a cidade, seja para uma construção discursiva positiva e negativa.

De acordo com Miranda (2002), até o final do século XIX, o Centro Histórico de Salvador era local de moradia das famílias mais nobres e, só em 1888, com a abolição da escravatura, essa população muda-se para outras áreas da cidade e o Centro Histórico começa a ser habitado por pessoas com menor poder aquisitivo, inclusive por imigrantes. Assim, entre as décadas de 70 e 80 do século XX, estabelece-se uma nova relação simbólica no local, considerando um constante processo de degradação: aumento da marginalidade, tráfico de drogas e estabelecimento de casas de prostituição. Sentidos de luxo e poder que preenchiam o lugar vão sendo substituídos por novos sentidos de pobreza, abrigo de marginais, enfim, de total desvalorização.

Em 1966 cria-se a Fundação do Patrimônio Artístico e Cultural da Bahia, hoje chamado de Instituto do Patrimônio Artístico e Cultural - IPAC, construído com a finalidade coordenar e gerenciar o plano de preservação e restauração do patrimônio arquitetônico do Centro Histórico de Salvador e em 1992 inicia-se de fato o processo de revitalização do local, no qual destacamos a manifestação de dizeres ancorados em, pelo menos, duas formações discursivas: uma ligada aos saberes administrativogovernamental, que autorizava dizeres que ressaltavam os benefícios que a revitalização traria à população, à modernização do local; por outro lado, surgiam dizeres oriundos de outra formação discursiva que afirmavam ser a revitalização uma exclusão da população local, já que, após a revitalização, a maioria dos antigos moradores não retornou às suas casas, que cederam lugar ao comércio. Oriundos desta formação discursiva, temos, por exemplo, os dizeres: “o Pelourinho não pertence mais ao seu povo", "o Pelourinho agora é lugar de rico", "vão acabar com a nossa cultura".

Neste processo de revitalização, alguns acontecimentos chamam atenção por sua relação simbólica com o local. Além de um ponto turístico, isto é, um lugar para visitantes, o Pelourinho é também considerado um lugar de resistência do povo negro, numa cidade de população, em sua maioria, negra. Rodas de capoeira e, principalmente, a presença de blocos afros são algumas marcas desta relação simbólica de resistência.

Também muito significante foi a instalação da Cruz Caída - escultura do artista plástico Mario Cravo, que estabelece uma relação simbólica de religiosidade, assim como 
uma relação de protesto pela demolição da antiga Catedral da Sé, anteriormente construída naquele local e demolida durante o processo de reurbanização da cidade.

A Igreja de São Francisco, a Catedral da Sé, a Igreja de Nossa Senhora do Rosário dos Pretos, entre outras igrejas, também são monumentos bastante visitados por turistas e pelo povo da cidade, que estabelecem uma relação simbólica com a fé cristã e, juntamente com elementos representantes das religiões de matrizes africanas, fazem parte do sincretismo religioso tão marcante na cidade do Salvador. Nas missas celebradas na Igreja de Nossa Senhora do Rosário dos Pretos, por exemplo, são tocados instrumentos do Candomblé, o que produz sentidos de uma convivência harmoniosa entre seguidores das duas religiões, além de uma não superioridade da religião cristã em relação às de matrizes africanas.

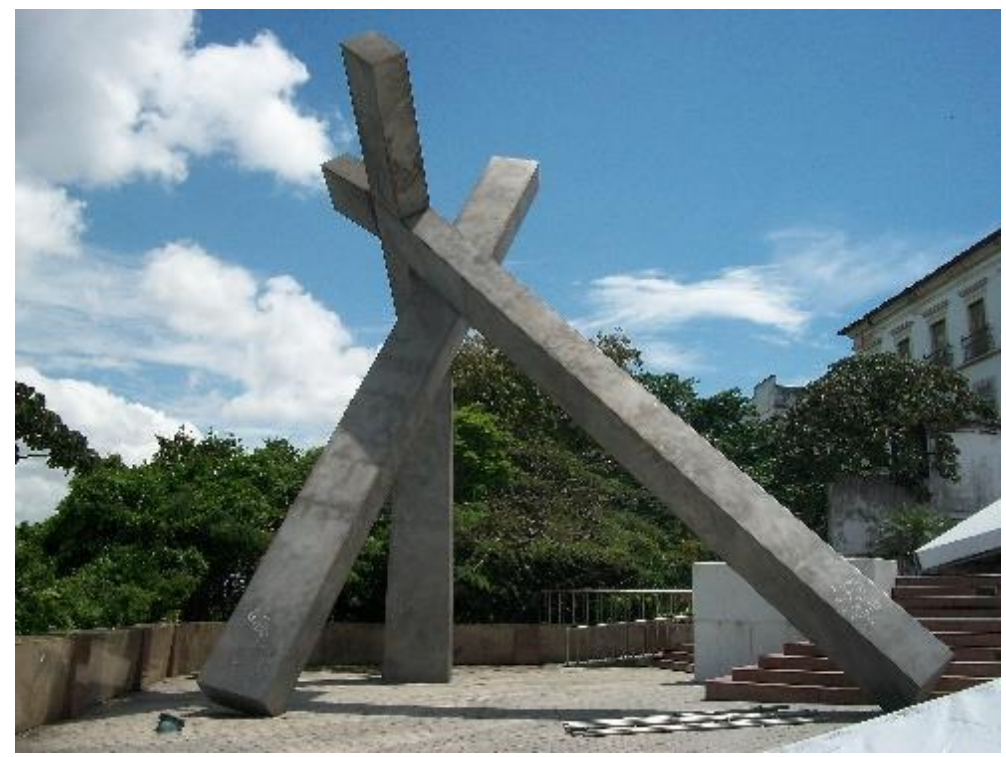

Figura 2: Cruz Caída. Fotografia de Gilberto Sobral.

Além dos sentidos aqui apresentados, muitos outros são possíveis a depender da relação simbólica que se estabelece com o referido espaço urbano, a qual está condicionada ao processo sócio-histórico dos sujeitos e que, portanto, não podemos dar conta.

\section{Olhares e sentidos no Beco da Energia}

Segundo Poppino (1986), Feira de Santana originou-se da Fazenda Olhos D'água, onde, semanalmente, realizava-se uma missa na capela da propriedade, o que possibilitou a formação de uma feira para abastecer fieis e viajantes. 
Segundo Oliveira (2008, p.20),

a inserção de Feira de Santana no cenário nacional implicou, para a sociedade feirense, reorganizar a cidade e seu cotidiano, alterando hábitos e construindo representações associadas a uma urbe comercial, progressista e moderna.

O município de Feira de Santana também é muito conhecido pelo Feiraguay, um centro comercial que, inicialmente, era uma feira livre, ou seja, organizada a céu aberto. Segundo Oliveira (2013, p. 32), hoje, o Feiraguay é um centro de compra

\begin{abstract}
não mais ambulante, tendo em vista que já se encontra em local fixo e protegido, o que foi garantido por ações do poder municipal - destacase não só pela acentuada quantidade de consumidores que a procuram para buscar desde um aparelho eletrônico a uma simples boneca, mas destaca-se principalmente por esses produtos serem, em sua maioria, contrabandeados, como indicam as frequentes apreensões de produtos sem nota fiscal feitas pela Polícia Federal no local.
\end{abstract}

Feira de Santana, como todo munícipio, também se caracteriza pelas zonas de prostituição. No entanto, não é comum um local de centro de cidade ocupado por casas de prostituição ter outra atividade que não seja esta.

Neste trabalho tomamos também como objeto de estudo a cidade de Feira de Santana, em particular, o Beco da Energia, antigo local conhecido somente pelas casas de prostituição e que tem passado por um processo de revitalização, que o tem transformado num espaço de cultura, fato que nos chamou a atenção.

O Beco da Energia, localizado no centro da cidade de Feira de Santana, entre as ruas Marechal Deodoro e Conselheiro Franco, funciona, há mais de 60 anos, como um lugar de casas de prostituição bastante simples, ou seja, tem uma clientela composta por pessoas de baixo poder aquisitivo. Resistindo ao tempo e à decadência local, abriga sete casas conhecidas pelos nomes de suas proprietárias.

Segundo Oliveira (2008, p.52),

mais que uma unidade, uma medida ou uma forma de delimitação de um espaço geográfico, o território é definido por uma apropriação que deles fazem os seus habitantes. Assim, o território ganha contornos a partir das múltiplas experiências vivenciadas e através das representações construídas sobre ele. Por meio das práticas e crenças sociais, são construídas as especificidades que permitem compor um sentimento de pertencimento, isto é, de territorialidade, capaz de definir os integrantes e os excluídos daquele espaço físico e sociocultural. Através das representações, cria-se e/ou se forja uma identidade, definindo os sujeitos pertencentes àquele lugar. 
O nome do local já nos faz pensar na não-transparência da linguagem. $O$ sintagma de energia possibilita a construção de sentidos diversos. Para os menos informados sobre a origem do lugar, energia pode estar ligada às atividades sexuais ali praticadas; para aqueles que conhecem melhor a história da cidade, esse nome é devido a uma antiga estação de distribuição elétrica da Coelba que ali funcionou por muitos anos. Também relacionar o local às suas atividades, agrega sentidos, por exemplo, ligados ao prazer, à diversão, a partir de uma formação discursiva cujos dizeres relativos à prostituição são positivos, mas também a sentidos de ameaça, exclusão, insegurança, que estão relacionados a outra formação discursiva, na qual há uma certa equivalência entre locais de prostituição e marginalidade etc.

Algumas ações vêm dando visibilidade ao Beco da Energia, despertando a atenção e o interesse de um público diverso - artistas, admiradores de uma variada manifestação artística, estudantes, pesquisadores, que tem alterado a rotina local.

É no Beco onde está a sede da APROFS - Associação dos Profissionais do Sexo de Feira de Santana, criada no ano de 2001 em parceria com a Secretaria Municipal de Saúde de Feira de Santana, para defender e garantir direitos das profissionais do ramo, além de realizar ações educativas e, principalmente, distribuir preservativos.

Foi, porém, em 2015, que um novo acontecimento representou um divisor na história do Beco, quando um grupo de grafiteiros concorreu ao edital Agitação Cultural Dinamização em Espaços Culturais da Bahia, do Governo do Estado.

Com o projeto Movimento "O Beco é Nosso", os artistas almejavam transformar o referido local numa galeria de arte e num espaço para outras manifestações culturais a céu aberto. Aos poucos, por exemplo, as paredes sujas do Beco foram sendo ocupadas por grafites, os quais, através de sua composição, contrastam com as velhas casas de prostituição, cujo sentido primeiro, talvez, seja o de abandono, passando a produzir sentidos, tais como de arte urbana, que dá voz àquele lugar. Na imagem seguinte observamos o desenho de um coração muito próximo à sua forma real, que, para algumas pessoas, produz, por exemplo, um sentido de vida que pulsa no local ao lado de imagens coloridas, algumas sem formas definidas, mas também como a de um rosto de mulher maquiada, enfeitada, que pode ser uma representação positiva das mulheres daquele lugar. 


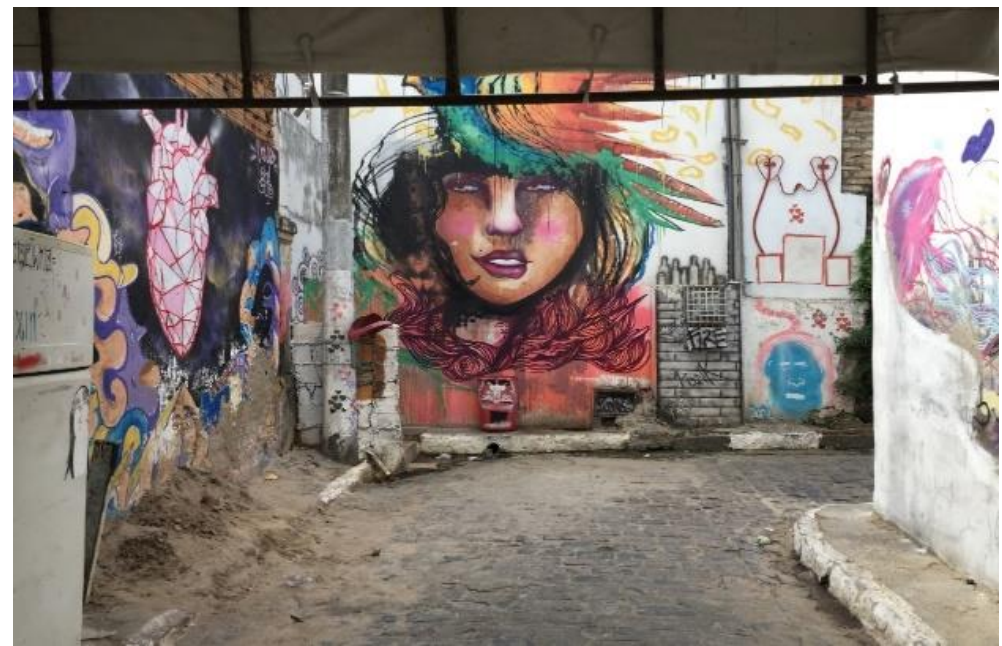

Figura 3: Beco da Energia. Fotografia de Gilberto Sobral.

O movimento provoca rupturas numa memória social e o local - até então preenchido pelos sentidos da promiscuidade, da prostituição, da exclusão social, por exemplo - é ressignificado como um lugar de convívio social, atenuando-se, desta forma, as tensões sociais entre as representações anteriores e o público do Beco e outros segmentos sociais. Além dos grafites, outras ações têm agitado o Beco, tais como um ensaio fotográfico e apresentações musicais.

O nome do projeto, Movimento "O Beco é Nosso", provoca um deslocamento do sentido de pertencimento daquele lugar, uma vez que o pronome possessivo nosso evoca um conjunto de pessoas. O Beco já não é somente das prostitutas que ali trabalham e de seus clientes, mas também dos artistas que realizam as intervenções e de todo o público que participa das novas atividades do local. Cria-se aí um sentido de acolhimento, o qual é contrário à toda violência da exclusão, do isolamento, da marginalização com que se costuma tratar os locais de prostituição. Dizer que o Beco é um local no qual se produz cultura e que, consequentemente, esta deve ser consumida, silencia outros dizeres que negativavam o lugar, pois o silenciamento é, também, uma forma de significar, uma vez que, em determinado lugar e momento sócio-histórico, o silêncio produz sentidos (ORLANDI, 2002). Tradicionalmente, aos profissionais do sexo é imposto um silêncio, que, além de colocá-lo à margem do convívio social, cria uma representação de promiscuidade, de pecador, entre outras, a partir de discursos relativos à moral, à religião, que lhe dão sentidos.

O processo de socialização promovido pelo Movimento "o Beco é nosso" devolve, de certa forma, um sentimento de cidadania anteriormente negado às pessoas daquele 
lugar. A promoção da cidadania deve ser uma iniciativa de todos, mas, principalmente, garantida constitucionalmente pelo Estado, o que, durante muitos anos, não ocorreu ali.

Também importante na construção de sentidos sobre o lugar foi a produção do documentário Beco da Energia: A (re) construção da consciência em uma identidade comunitária, que foi produzido pelos alunos do sétimo semestre do curso de Psicologia da Faculdade de Tecnologias e Ciências - Campus Feira de Santana. A partir desse documentário, percebe-se que o movimento de revitalização do Beco não produziu somente sentidos de valorização, não promoveu somente uma ressocialização. Algumas mulheres, prostitutas ou donas das casas de prostituição, consideram que o movimento, por dar visibilidade ao local, também afastou muitos clientes que passaram a ter receio de serem vistos no local. Se por um lado, o movimento promove a inclusão social, por outro, interfere negativamente na economia com a diminuição da clientela.

Não se pode negar que, atualmente, as mais diversas questões que envolvem a sexualidade são discutidas com mais naturalidade por alguns setores da sociedade, mas ainda persistem aqueles sentidos mais conservadores. Não seria diferente com a prostituição. No documentário, percebe-se que as mulheres daquele lugar subjetivam-se a partir de interpelações ideológicas distintas. Sendo a formação discursiva aquilo que pode e deve ser dito, a manifestação da formação ideológica na linguagem, há sujeitos que reproduzem dizeres de uma FD conservadora em relação à prostituição, tais como "esta não é uma vida digna", "bicho de sete cabeças", "isso aqui é humilhação" assim como a reprodução de dizeres de outra FD que considera a atividade ali desenvolvida de forma positiva como algo digno, tais como "isso aqui é um trabalho bom", "aqui não é só aquilo que o povo pensa", "há mães trabalhando para sustentar sua família". Percebe-se, assim, que são reproduzidos saberes, entre tantos outros, de duas formações discursivas: aqueles que dignificam a atividade por ser exercida por mães que, daquela atividade, conseguem oferecer uma vida mais digna para sua família - ou seja, é uma atividade de dedicação e amor - e saberes que enfatizam a atividade como algo nefasto pela venda de sexo por dinheiro.

\section{O corpo enquanto materialidade discursiva}

Considerando que o discurso se materializa de diversas formas, não poderíamos deixar de tratar do corpo como uma materialidade muito significativa nos espaços 
urbanos aqui estudados, o qual se constrói discursivamente. Não trataremos, aqui, do corpo empírico, mas do corpo na sua dimensão simbólica, isto é, no que diz respeito aos sentidos que produz por gestos de interpretação pela memória discursiva, ou seja, um conjunto de já ditos que sustentam todo o dizer. Realizaremos, aqui, algumas reflexões que permitam entender de que maneira o corpo pode ser significado na e pela linguagem.

Segundo Pêcheux (1999, p.50), “a memória deve ser entendida a partir dos sentidos entrecruzados da memória mítica, da memória social inscrita em práticas, e da memória construída do historiador", e assim passam a fazer parte da memória social, na qual estão os discursos que circularam e circulam na sociedade.

Todo espaço urbano é ocupado por corpos que muito têm a dizer daquele lugar e sempre vistos a partir das suas condições reais de existência, do olhar que nele é lançado, seja por aqueles que ali trabalham ou frequentam, seja por uma visão exterior.

Considerando alguns já-ditos que sustentam novos dizeres, a um corpo malhado, escultural, isto é, aquele determinado pelos atuais padrões de beleza, por exemplo, é comum circularem sentidos positivos como saúde, beleza, jovialidade e, em relação aos homens, masculinidade, virilidade, mas também sentidos negativos, como o de quem cultua excessivamente o corpo negligencia o intelecto; entretanto, em relação a um corpo mais robusto, que foge a estes mesmos tradicionais padrões de beleza, podem circular sentidos de falta de saúde, desleixo, mas também de liberdade a estes padrões, por exemplo. No interdiscurso, os dizeres vão sendo recuperados e atualizados a partir do lugar de onde se subjetiva.

Por ser o Centro Histórico de Salvador simbolicamente marcado como lugar de resistência e por, historicamente, ter sido construída uma imagem estereotipada do povo negro, no local, há uma tendência na criação de imagens coletivas de virilidade, de força física, em relação ao homem negro que trabalha, que dança a capoeira, enfim que transita no Pelourinho, bem como em relação à mulher por suas formas avantajadas, que se manifestam na linguagem em dizeres tais como o/a negro(a) é bom de cama, tem pegada, os negros são os mais bem dotados, entre outros, como se todos fossem fisicamente iguais e assim se comportassem e que silenciam a força de trabalho que estes mesmos corpos representam.

No Beco o corpo que comumente produz/circula sentidos é o da mulher e está intimamente relacionado à atividade sexual, mas, como é sabido, a depender do lugar 
de onde se subjetiva, sentidos diversos são produzidos. Tradicionalmente, levando em consideração um olhar externo e toda construção sócio-histórica das trabalhadoras de casas de prostituição, é comum a repetição de alguns dizeres, tais como: os corpos das mulheres que ali trabalham são sujos, transmissores de doença, pecadores, mas também corpos desejosos, sensuais, considerando aqueles que consomem estes corpos. No entanto, quando pensado a partir de olhares internos, os corpos que ali trabalham ganham sentidos de orgulho, de força de trabalho, são corpos de mães, de chefes de família, de trabalhadoras.

\section{Conclusão}

Pensar a cidade, seja através de sua estrutura física ou pela forma como os seus habitantes e/ou visitantes ocupam um determinado espaço, é uma maneira de compreender como se dão as relações sociais num determinado momento sóciohistórico.

Apesar de o Centro Histórico de Salvador e o Beco da Energia serem dois lugares marcados por processos de revitalização, amplamente divulgados, atualmente, produzem, muitas vezes, sentidos distintos. Enquanto o Beco da Energia é cada vez mais procurado pela população em geral e, em particular, por pesquisadores, em virtude das manifestações artísticas que ali ocorrem, produzindo sentidos positivos deste lugar, o Centro Histórico de Salvador é, cada vez mais, preenchido por sentidos oriundos de formações discursivas de abandono e insegurança, o que tem afastado, principalmente, a população local, sendo mais frequentado por turistas, que recuperam já-ditos autorizados por formações discursivas que enaltecem a beleza e o povo do lugar, mas que facilmente são substituídos por dizeres que retratam a precariedade em que se encontra o Pelourinho, o que permite afirmar que os sentidos estão sempre em movimento, mesmo parecendo estabilizados quando oriundos de uma determinada formação discursiva.

Aqui apresentamos sentidos possíveis no/sobre os espaços urbanos em questão, os quais manifestam na linguagem algumas práticas sociais dos sujeitos que neles circulam. 


\section{Referências}

MIRANDA, Luciete B. e SOLEDADE, Maria Aparecida C. S. Pelourinho: desenvolvimento socioeconômico. Salvador: Secretaria da Cultura e Turismo, 2002.

OLIVEIRA, Ana Maria Carvalho dos Santos. Feira de Santana em tempos de modernidade: olhares, imagens e práticas do cotidiano (1950-1960). Tese. Recife: 2008.

OLIVEIRA, Patrícia Medeiros de. Formação e legalização do Feiraguai. 107 p. Dissertação. Universidade do Estado da Bahia. Salvador, 2013.

ORLANDI, Eni. P. Análise de discurso: princípios e procedimentos. 10 ed. Campinas, SP: Pontes, 2012.

Análise de discurso. In: ORLANDI, Eni P.; LAGAZZI-RODRIGUES, Suzi (Orgs.). Discurso e textualidade. Campinas. SP: Pontes, 2006.

Cidade dos sentidos. Campinas, SP: Pontes, 2004.

As formas do silêncio: no movimento dos sentidos. Campinas, SP: Editora da UNICAMP, 2002.

Cidade atravessada: os sentidos públicos no espaço urbano. Campinas, SP: Pontes, 2001.

Recebido em 16/07/2017

Aceito em 07/09/2017. 